\title{
A Proposed Integrated Approach for BI and GIS in Health Sector to Support Decision Makers (BIGIS-DSS)
}

\author{
Torky Sultan \\ Information System Dept. \\ Faculty of Computer and Information \\ Systems, Helwan University, \\ Cairo, Egypt \\ Mona Nasr \\ Information System Dept. \\ Faculty of Computer and Information \\ Systems, Helwan University, \\ Cairo, Egypt
}

\author{
Ayman Khedr \\ Information System Dept. \\ Faculty of Computer and Information \\ Systems, Helwan University, \\ Cairo, Egypt \\ Randa Abdou \\ Information System Dept. \\ Faculty of Computer and Information \\ Systems, Helwan University, \\ Cairo, Egypt
}

\begin{abstract}
This paper explores the possibilities of adopting Business Intelligence (BI), and Geographic Information System (GIS) to build a spatial intelligence and predictive analytical approach. The proposed approach will help in solving spatial problem which faces decision makers at health sector. The proposed spatial analytical approach will cover three main health planning issues. These issues are tackling health inequalities through geospatial monitor for inequalities in distribution of health units and its services, support decision-making with predictive analytics for common health indicators, and geoprocessing for input layers through dynamic health map and motion charts to support decision making.
\end{abstract}

Keywords- Business Intelligence (BI); Geographic Information System (GIS); Decision Support System (DSS))

\section{INTRODUCTION}

Historically, BI and GIS technologies have followed separate development and implementation paths [10].Decision makers in health sector request for a more complete operational picture and the ability to be more proactive have led to the combination of these two technologies to have suitable tool for Decision Support System (DSS).

Recently, A modern and effective spatial DSS having all the requisite support technologies like online analytical processing (OLAP), specialized analysis and reporting is required for future planners and decision makers; new and efficient methods are needed to integrate the related Information technologies to discover knowledge from large spatial databases [21]

Existing studies focused on spatial and numerical problem solving by using online analytical processing
OLAP and GIS system combined to develop the Spatial OLAP Visualization and Analysis Tool (SOVAT) which currently used to solve problems that faces decision maker at health sector as shown in Fig. 1[21].

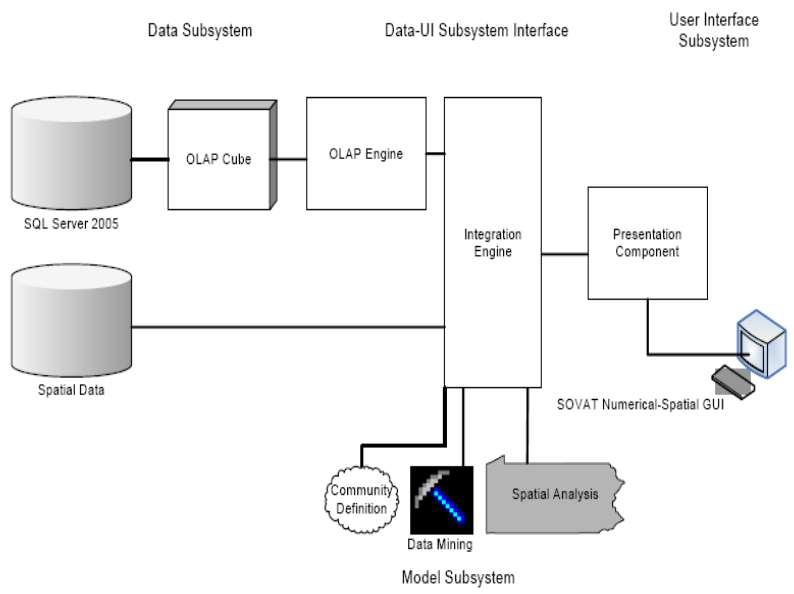

Fig 1 :OlAP-GIS Architecture. Source: University of Pittsburgh 2006

The development of numerical-spatial routines is frequently required to solve complex problems. Individuals who use decision support technology need a system that is capable of supporting the development of numerical-spatial routines integrated with predictive analytical tool.

GIS are designed for the visualization of spatial data and are not perfectly suited for space-time data. That's because today's GIS are built on spatial[18], rather than space-time data structures, GIS maps are static, while the underlying data are dynamic, visualization and the analysis of dynamic marketplace data will benefit greatly from tools that allow the 
user to animate and interact with maps and graphical data views.

Current geographic knowledge discovery (GKD) methods generally use very simple representations of geographic objects and spatial relationships. Geographic data mining methods should recognize more complex geographic objects (i.e. lines and polygons) and relationships (i.e. non-Euclidean distances, direction, connectivity, and interaction through attributed geographic space such as terrain). Furthermore, the time dimension needs to be more fully integrated into these geographic representations and relationships.

Therefore, having a spatial temporal analysis capability could provide an alternate way to look at public health information. Presenting information with a spatial component triggers a different thought process than seeing the same information on a table or a grid and guide decision maker brainstorm for new possibilities.

Traditional DSS use relational database generators (the middle components that represent the unique software included in the system and are built by the DSS tools) to store the numerical data. GIS is essential for developing spatial routines. There is no alternative technology that could simulate this process.

Therefore it must be coupled with a BI that can, by itself, support development of powerful temporal-numerical routines [21]. In addition, it must enable for the development of an interface that supports not only the combination of numerical and spatial information display, but also a temporal interactive easy-to-use environment for creating different types of numerical and spatial routines. As the result, the potential of this synergy is an approach that can significantly enhance spatial, temporal and numerical problem solving through predicative concept

\section{RELATED WORK}

The increasing availability of (GIS) in health organizations, together with the proliferation of spatially disaggregate data, has led to a number of studies that have been concerned with developing measures of access to health care services. The main aim of this section is to review the use of GIS-based measures in exploring the relationship between geographic access, utilization, quality and health outcomes. There are previous studies in this area. - At first studies about the uses of geography information system in the field of health, for tracking the spread of a disease such as cancer or research area[15]. The second studies in health indicators and tackling health inequalities but don't use spatial predicative tool to support decision makers [7] .

The third studies rely on static spatial tool to make analytical process but not in different time frame [18]. The fourth study an OLAP-GIS technology [2], It is developed at the University of Pittsburgh, The inputs of this research are depend on both OLAP and GIS technologies stand alone as depicted in Table 1 but the outputs of this study is to combine OLAP AND GIS technologies but it has no predicative and temporal concept as shown in Table 2
TABLE 1: DSS GENERATORS FOR DECISION SUPPORT AND CAPABILITIES THEY PROVIDE SOURCE: UNIVERSITY OF PITTSBURGH 2006

\begin{tabular}{|c|c|c|c|c|c|c|c|c|}
\hline & $\begin{array}{l}\text { Interesting } \\
\text { Patterns/ } \\
\text { Knowledge } \\
\text { Discovery }\end{array}$ & $\begin{array}{c}\text { Large, } \\
\text { Complex } \\
\text { Data } \\
\text { Sets }\end{array}$ & $\begin{array}{c}\text { Multidimensional } \\
\text { View/ } \\
\text { Navigation }\end{array}$ & $\begin{array}{c}\text { Statistical } \\
\text { Analysis }\end{array}$ & $\begin{array}{c}\text { Spatial } \\
\text { Presentation }\end{array}$ & $\begin{array}{l}\text { Visual } \\
\text { Charts }\end{array}$ & $\begin{array}{l}\text { Spatial } \\
\text { Analysis }\end{array}$ & $\begin{array}{l}\text { Numerical- } \\
\text { Spatial } \\
\text { Problem } \\
\text { Solving } \\
\end{array}$ \\
\hline $\begin{array}{l}\text { Statistical } \\
\text { Software } \\
\end{array}$ & & & & X & & $\mathrm{X}$ & & \\
\hline $\begin{array}{c}\text { Data } \\
\text { Mining }\end{array}$ & $\mathrm{X}$ & & & $X$ & & $\mathrm{X}$ & & \\
\hline $\begin{array}{c}\text { GIS } \\
\text { Software }\end{array}$ & & & & & X & & $\mathrm{X}$ & \\
\hline $\begin{array}{c}\text { Relational } \\
\text { DB } \\
\end{array}$ & & X & & & & & & \\
\hline OLAP & & X & X & & & X & & \\
\hline
\end{tabular}

TABLE 2: TRADITIONAL DSS GENERATORS VERSUS AN OLAP-GIS SYSTEM: SOURCE: UNIVERSITY OF PITTSBURGH 2006

\begin{tabular}{|c|c|c|c|c|c|c|c|c|}
\hline & $\begin{array}{c}\text { Interesting } \\
\text { Patterns/ } \\
\text { Knowledge } \\
\text { Discovery }\end{array}$ & $\begin{array}{l}\text { Large, } \\
\text { Complex } \\
\text { Data } \\
\text { Sets }\end{array}$ & $\begin{array}{c}\text { Multidimensional } \\
\text { View/ } \\
\text { Navigation }\end{array}$ & $\begin{array}{l}\text { Statistical } \\
\text { Analysis }\end{array}$ & $\begin{array}{c}\text { Spatial } \\
\text { Presentation }\end{array}$ & $\begin{array}{l}\text { Visual } \\
\text { Charts }\end{array}$ & $\begin{array}{l}\text { Spatial } \\
\text { Analysis }\end{array}$ & $\begin{array}{c}\text { Numerical- } \\
\text { Spatial } \\
\text { Problem } \\
\text { Solving } \\
\end{array}$ \\
\hline $\begin{array}{l}\text { Statisical } \\
\text { Sotwrare } \\
\end{array}$ & & & & $X$ & & $X$ & & \\
\hline Data Mining & $X$ & & & $\mathrm{X}$ & & $X$ & & \\
\hline $\begin{array}{c}\text { GIS } \\
\text { Software }\end{array}$ & & & & & $X$ & & X & \\
\hline $\begin{array}{c}\text { Relational } \\
\text { DB }\end{array}$ & & X & & & & & & \\
\hline OLAP & & $X$ & $X$ & & & $X$ & & \\
\hline OLAP-GIS & $\mathrm{X}$ & $\mathrm{X}$ & $\mathrm{X}$ & $\mathrm{X}$ & $\mathrm{X}$ & $\mathrm{X}$ & $\mathrm{X}$ & $X$ \\
\hline
\end{tabular}

The outputs of this study is using proposed BIGIS_DSS approach to solve health inequality spatial problem which faces decision maker at health sector as shown in Table 4.

But Reporting and analytics are two different practices that have different goals, methods, sponsors, funding, and enabling technologies. Yet many people are being confused between both of them, perhaps because most vendors' platforms for business intelligence (BI) include functions for various types of reporting and summarized analysis in the form of (OLAP)[20].

By comparison, predictive analytics (which includes techniques for data mining and forecasting) is far more exploratory and forward-looking than reporting and (OLAP)[20].The value of predictive analytics is the discovery of unknown facts and relationships, the confirmation of known or suspected relationships, and the leverage of those relationships for better decision making [20].

Achieving these discovery-driven goals through reporting is unlikely, since most reports are based on a small amount of summarized information that's already well known and studied. Likewise, OLAP is usually implemented as a form of parameterized reporting, where the parameters represent dimensions. In such implementations, the available parameters limit the breadth of the analysis, and the analysis cannot be broadened without technical personnel developing more parameters. Table 3 summarizes the differences between reporting and analytics 
TABle 3: THE DifFERENCES BETWEen REPORTING AND ANALytics

\begin{tabular}{|c|c|c|}
\hline & Reporting and OLAP & $\begin{array}{l}\text { Advanced Analytics, Both } \\
\text { Query-Based and Predictive }\end{array}$ \\
\hline $\begin{array}{l}\text { Business } \\
\text { Method }\end{array}$ & $\begin{array}{l}\text { Performance management for } \\
\text { business entities, relative to } \\
\text { a business plan. }\end{array}$ & $\begin{array}{l}\text { Develop new products, } \\
\text { customers, etc. Reduce cost, } \\
\text { risk, fraud. }\end{array}$ \\
\hline $\begin{array}{l}\text { Information } \\
\text { Purpose }\end{array}$ & $\begin{array}{l}\text { Update known facts. } \\
\text { Quantify past performance. }\end{array}$ & $\begin{array}{l}\text { Infer unknown facts and } \\
\text { relationships. Quantify } \\
\text { future probabilities. }\end{array}$ \\
\hline Output & $\begin{array}{l}\text { Historical standard reports, } \\
\text { dashboards, metrics, KPIs, } \\
\text { cubes for OLAP, etc. }\end{array}$ & $\begin{array}{l}\text { Predictive models, scores, } \\
\text { forecasts. Results of complex } \\
\text { queries. Insights. }\end{array}$ \\
\hline Queries & $\begin{array}{l}\text { Known, simple queries that } \\
\text { are easily optimized. }\end{array}$ & $\begin{array}{l}\text { Queries that become very complex } \\
\text { as they evolve via iteration. }\end{array}$ \\
\hline $\begin{array}{l}\text { Volume } \\
\text { per Query }\end{array}$ & $\begin{array}{l}\text { Small (usually less than } \\
\text { a gigabyte). }\end{array}$ & Large (possibly terabytes). \\
\hline
\end{tabular}

TABle 4: Bigis_Dss Proposed APPROACH For SOlVING HeAlth INEQUALITY SPATIAL PROBLEM

\begin{tabular}{|c|c|c|c|c|c|c|c|c|c|}
\hline & $\begin{array}{c}\text { Intersting } \\
\text { Pattems } \\
\text { Knowildge } \\
\text { Discoreryy } \\
\end{array}$ & $\begin{array}{c}\text { Large, } \\
\text { Complex } \\
\text { Datha } \\
\text { Sets } \\
\end{array}$ & $\begin{array}{c}\text { Vuldidimensional } \\
\text { View/ } \\
\text { Narigation }\end{array}$ & $\begin{array}{l}\text { Stansitical } \\
\text { Analysis }\end{array}$ & $\begin{array}{c}\text { Spatial } \\
\text { Presentation }\end{array}$ & $\begin{array}{l}\text { Visval } \\
\text { Charts }\end{array}$ & $\begin{array}{l}\text { Spatail } \\
\text { Anaysis }\end{array}$ & $\begin{array}{c}\text { Numerical- } \\
\text { Spatial } \\
\text { Problem } \\
\text { Soling } \\
\end{array}$ & $\begin{array}{l}\text { Health lnequalitie } \\
\text { Spatial problem } \\
\text { Solving }\end{array}$ \\
\hline $\begin{array}{l}\text { Stantistal } \\
\text { Softruare }\end{array}$ & & & & X & & X & & & \\
\hline Data VIning & X & & & X & & X & & & \\
\hline $\begin{array}{c}\text { GIS } \\
\text { Softrare }\end{array}$ & & & & & X & & X & & \\
\hline $\begin{array}{c}\text { Relational } \\
\text { DB } \\
\end{array}$ & & X & & & & & & & \\
\hline OLAP & & X & X & & & X & & & \\
\hline OLAP-GIS & X & X & X & 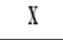 & X & X & X & $X$ & \\
\hline II-GIS-DSS & X & X & X & $X$ & $\mathrm{X}$ & X & $X$ & $X$ & X \\
\hline
\end{tabular}

Therefore, There is a need for proposed approach to mix GIS,MIS and BI and make them work together to facilitate decision support among varied sections[3].

\section{PROPOSED BIGIS_DSS APPROACH} health

This combination should mend to cover all areas in public

The main aim of this paper is building a spatial intelligence and predictive analytics approach for solving spatial problem which faces decision makers at health sector as shown in Fig. 2.

-The approach include four phases:

\section{A. Phase I:}

Build Geodatabase which include spatial data and non spatial data, spatial data like :

Governorates layer,Streets layer,Rivers layer,

Buildings layer,Usage layer,Borders layer,All of these layers called base map layers

-Non spatial data like

Health data, Health Indicators (as listed below) Health Services, Disease data, Censes information, Health coverage areas information, (We can use database engine like oracle $11 \mathrm{~g}$ to build this geodatabase ).

The following list includes common indicators at health sector:-

-Demographic Indicators

-Health / services Indicators

-Health /Communicable diseases

-Health /non Communicable diseases

- Health Manpower Indicators

-Health Care Indicators

-Nutritional Indicators

-Morbidity Indicators

-Indicators of Resources, Access, and Coverage

-Health facility indicators

-Mortality Indicators

\section{B. Phase II:}

Build Data Warehouse schema for our geodatabase which enable multi functions like enter query, design charts, analyzing model ,techniques and reporting

\section{Phase III:}

Geoprocessing to convert our data warehouse schema to spatial data warehouse schema using (BI) techniques and spatial model builder tool to build outputs dynamic maps, forecasting and spatial analytical for all common health indicators which effect on health sector

\section{Phase IV:}

Spatial BIGIS-DSS depend on space-time query to support decision maker at health sector

The aim of this paper is achieved after phase IV implementation for having a spatial intelligence and predictive analytics approach, that'll be used for solving spatial problem which faces decision makers at health sector like health inequalities and non served areas by healthcare.

The proposed approach can help decision makers to solve health problem and restructure the distribution of health units in new areas which outcome from the predicative analytics from the proposed approach and put their expectation for any new health units in future. As well as to predict the spread of diseases and geographical epidemiology epidemics and the spread of disease foci(hotspots) in future .

There is a clear need for an application that is capable of collecting, organizing, and storing temporally and spatially distributed indicator data, generation of maps and other charts. The need for (as listed below) that can eventually be used for the good quality data is an obvious, but unfortunately often overlooked [15], prerequisite to generating high quality thematic maps and analysis from data. It is this gap in quality data collection and organization that proposed standard approach seeks to fill. 
Data mining offers great potential benefits for GIS-based applied decision-making. Recently, the task of integrating these two technologies has become of critical importance, especially as various public and private sector organizations possessing huge databases with thematic and geographically referenced data begin to realize the huge potential of the information contained therein.

Challenges in spatial mining: Geospatial data repositories tend to be very large. Moreover, existing GIS datasets are often splintered into feature and attribute components that are conventionally archived in hybrid data management systems. Algorithmic requirements differ substantially for relational (attribute) data management and for topological (feature) data management. [35]

Related to this is the range and diversity of geographic data formats, which present unique challenges. The digital geographic data revolution is creating new types of data formats beyond the traditional "vector" and "raster" formats. Geographic data repositories increasingly include illstructured data, such as imagery and geo-referenced multimedia [22].

\section{BIGIS_DSS APPROACH FEATURES}

As mentioned earlier in this paper eventually lead to a better understanding of the relationship between the adoption of BI,GIS,DSS process and its impact in a health sector environments. This section discusses the BIGIS_DSS Approach Features.

Spatial data mining is the application of data mining methods to spatial data. The end objective of spatial data mining is to find patterns in data with respect to geography. So far, data mining and Geographic Information Systems (GIS) have existed as two separate technologies, each with its own methods, traditions, and approaches to visualization and data analysis. Particularly, most contemporary GIS have only very basic spatial analysis functionality. The immense explosion in geographically referenced data occasioned by developments in IT, digital mapping, remote sensing, and the global diffusion of GIS emphasize the importance of developing data-driven inductive approaches to geographical analysis and modeling.

The paper's aim is exploratory, building towards understanding and subsequently towards constructive guidance for the adoption process of new technologies in such as BI, GIS and motion charts, sometimes in hospitable, health environments. Since the paper deals with poorly understood issues in a rich, difficult to control environment, caution ought to be taken in assessing the results. However, taking the exploratory design's restraints into account, two theoretical contributions can be derived:

1-Drawing attention to identified potential new technology adoption approach such as BI,GIS and DSS that determine spatial intelligence and predictive analytics for solving spatial problem which faces decision makers at health sector .

2- Discussing how the successful adoption of a new approach increases its impact in health sector environments.

\section{Proposed BIGIS_DSSSApproach}

GeoSpatial BI for DSS

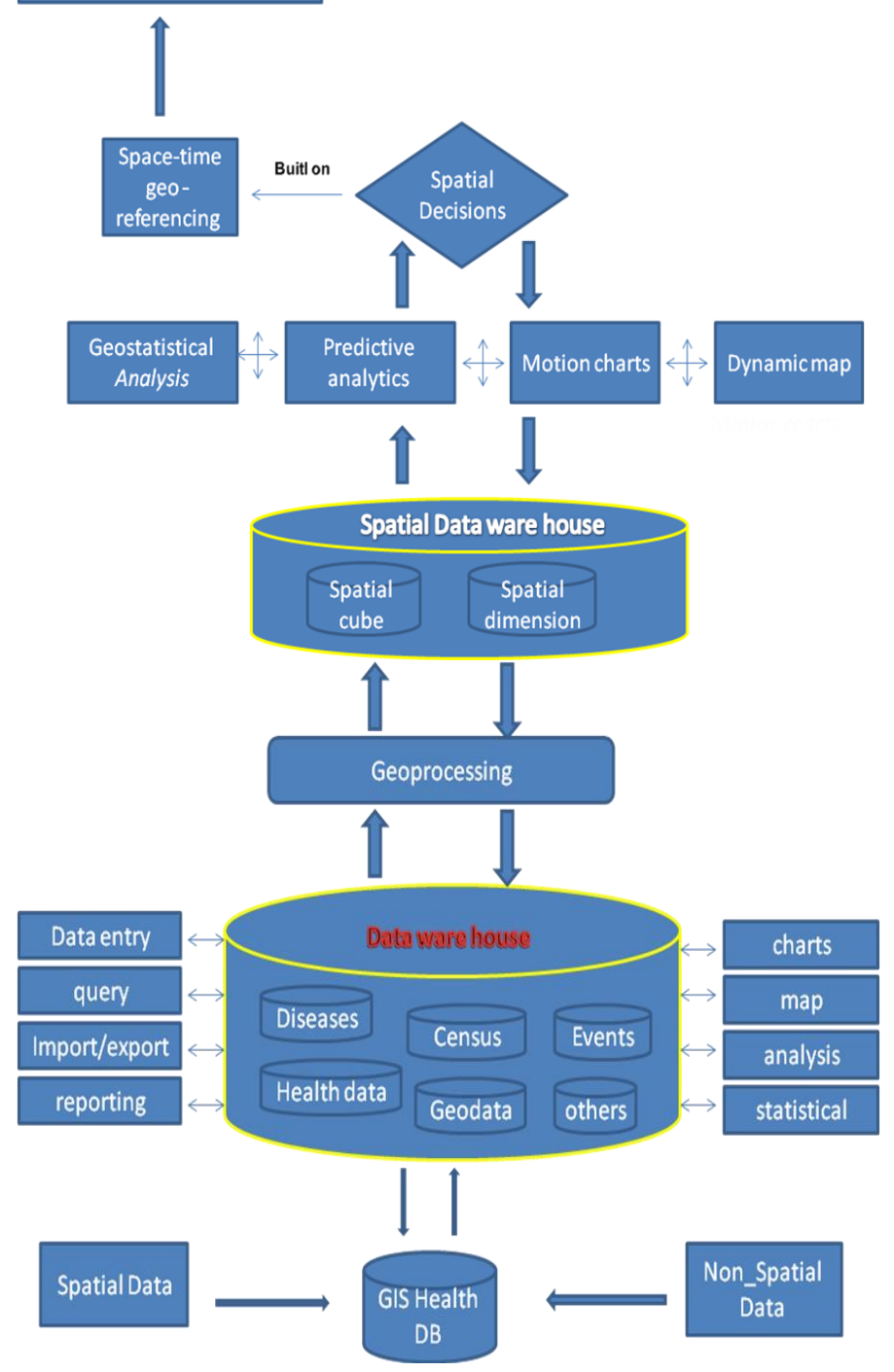

Fig. 2: The Proposed BIGIS-DSS Approach at Health Sector

As wide as the possible applicability of the study is, the claim to managerial contribution should be just as modest. An exploratory study cannot provide normative [18]. The reason for this is that case studies in principle can only establish the existence of relations but not their direction [19]. In other words, it is only possible to conclude that one variable is related to another variable, but impossible to determine the dependent and independent one. In addition, generalizing from a single case study however carefully selected cannot be justified [20] Nonetheless given these constraints, this paper will be useful to the following stakeholders:

1-Senior managers of the health departments who develop and improve health services should be interested in the results, because the results deal with a management issue of strategic importance database which found in BI\&GIS servers as in Fig. 3. 
Therefore this paper will combine a number of international health indicators and indicators associated spatial analysis and the work necessary to extract the proposed standard approach criteria for health indicators can be used in the spatial scope of local and international health.

This paper expects that combining the strength in predicate analysis and the ease of use makes the proposed approach ideal for healthcare professionals without extensive computer skills. And also expects that the maps resulting from the proposed approach will provide decision makers with information to strengthen their disaster management capacity. It also will represent the basis for the reflection that needs to take place regarding populations' vulnerability towards natural hazards from a health perspective as shown in Figure 4

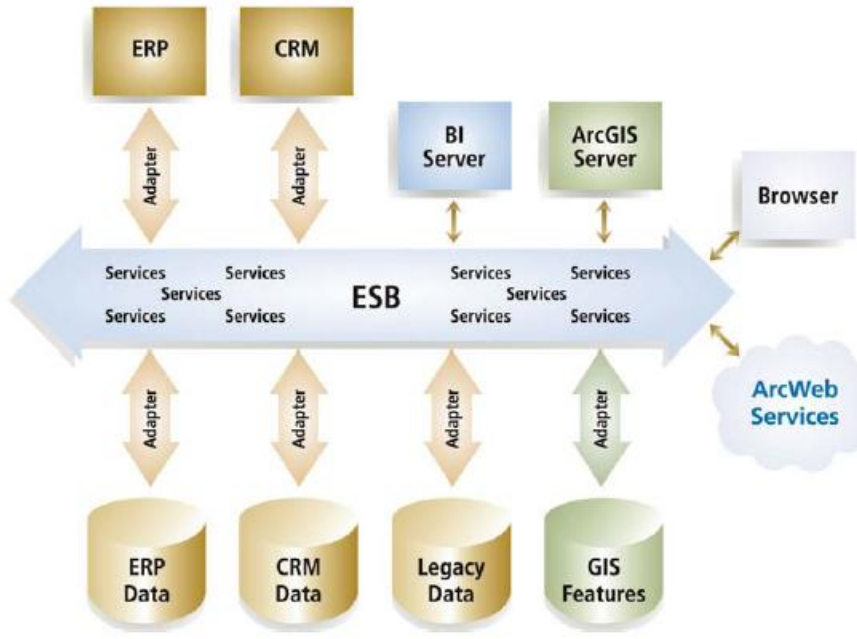

Fig 3:

A simplified view of service-oriented architecture utilizing the enterprise service bus (ESB) to pass services between various applications. Applications in ArcGIS Server can use aggregated data managed by the BI server and utilize its reporting platform. The ArcGIS Server could also use enterprise resource planning (ERP) or CRM data via a service independent of the BI server.

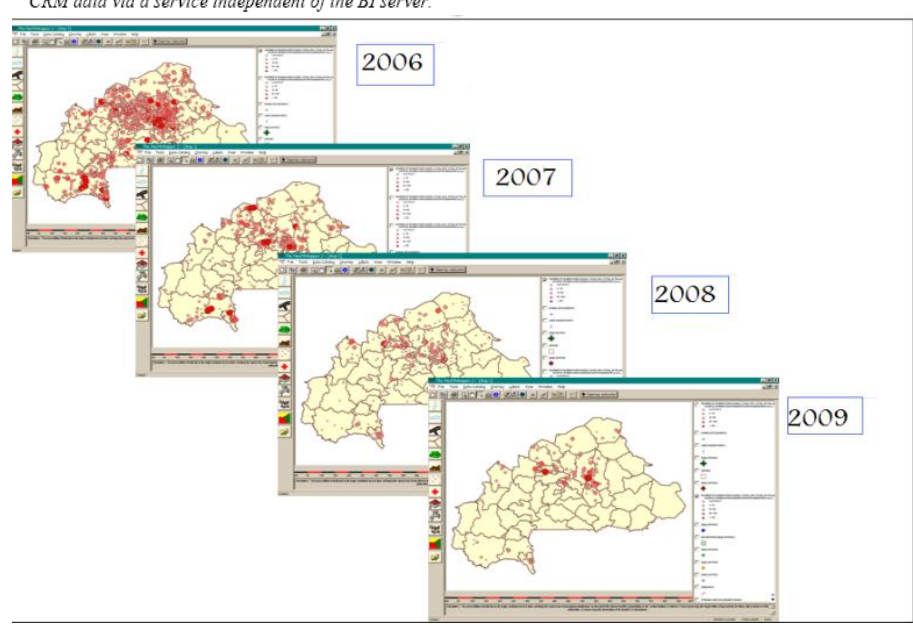

Fig. 4: Comparison between Health Maps in Different Years

Source :WHO site [information system department],2009

The approach covers the following items:

1-Reviewing that there are a variety of health indicators, according to several different destinations of health sector.
2-Attempt to provide a set of indicators to cover the full breadth of the approach. Identification of the spatial location of a geographic community by using GIS, Identification of health factors within the community by using numerical data such as death counts, disease incidence or prevalence rates, Identification of the spatial location of bordering communities of interest using GIS.

3- Development of a dynamic proposed spatial approach for health information and indicators

4-Implementing the proposed approach by inserting the health information and comparing subset of health indicators before and after using the proposed spatial approach of health indicators to display the difference and how the proposed approach can help in tackling health inequalities

5-Reviewing that spatial approach of health indicators will enhance presentation of the health inequalities dimensions at the health sector .

6-Using spatial approach of health indicators for DSS to improve health sector.

\section{The Proposed Methodlogy}

-This paper depend on the following methodology to implement the proposed approach :-

Phase I : Data collection phase (spatial data and row data)

Phase II : Building geodatabase through different software integration and insert data to database

Phase III : Developing proposed approach by using different integration tools

Phase IV : Data analyzing and processing depend on spatial statistical analyze tool for geodatabase of health indicators.

Phase V : Test the output of information through development proposed spatial analytical approach for health information indicators

Phase VI : Produce dynamic health map for DSS and follow up phase through implementation of DSS process for health indicators to restructure all resources, as shown in Figure 5.

\section{SITE SELECTION}

Identifying a new service location is one of the most basic functions of business development. Having the ability to quickly access the geodemographic dynamics of health sector in contrast to the likely demand for services at a new location requires flexible powerful analytical software tools.

ArcGIS desktop, Business Analyst, ArcGIS server ,geoprocessing , OLAP and BusinessMAP PRO software all provide varying levels of capabilities for site selection and combination between all of them is suitable for initial design for proposed approach as shown in Figure 5. 


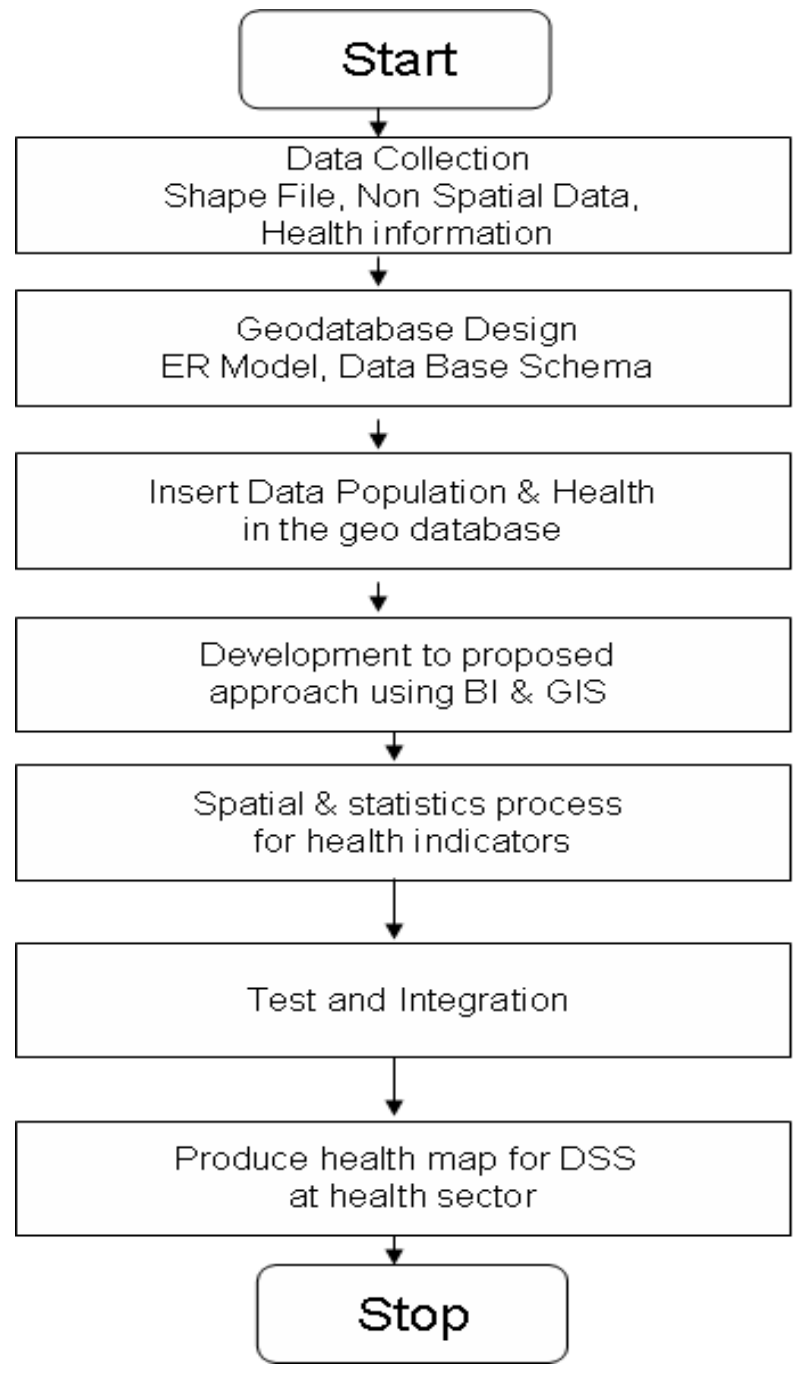

Fig. 5 : Methodology Phases

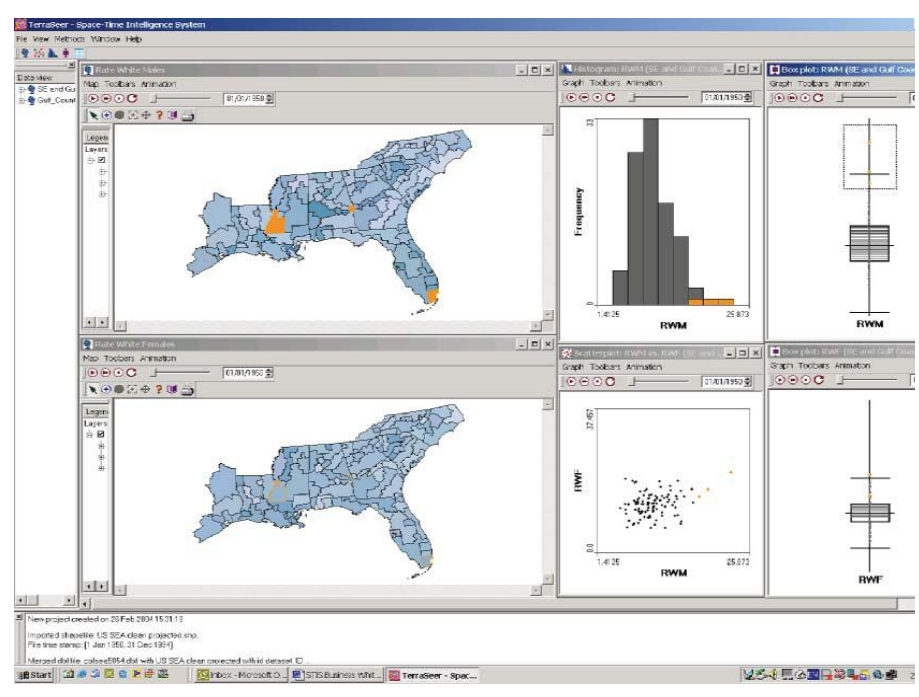

Fig. 6 : The Proposed Approach with Different software

\section{CONCLUSION AND FUTURE WORK}

BIGIS-DSS proposed approach enhances OLAP-GIS at health sector by making adoption of BI,GIS and DSS technologies to build a spatial intelligence and predictive analytics approach for solving spatial problem which faces decision makers at health sector. The proposed spatial analytical approach will cover three main health planning issues. These issues are tackling health inequalities through geospatial monitor for inequalities in distribution of health units and its services, support decision-making with predictive analytics for common health indicators, and geoprocessing for input layers through dynamic health map and motion charts to support decision making. This paper shows that combining is the strength in predicate analysis and the ease of use makes the proposed approach ideal for healthcare professionals without extensive computer skills. The maps resulting from the proposed approach will provide decision makers with information to strengthen their disaster management capacity. It also will represent the basis for the reflection that needs to take place regarding populations' vulnerability towards natural hazards from a health perspective. BIGIS-DSS approach is able to be integrated and cooperated with other sciences through different types of information systems and, it can be used as a new direction that will be deployed for both national and international development business. The proposed approach can be considered as a nucleus to increase the economy of developing countries at health sector.

The results demonstrate the potential for BIGIS_DSS in health sector analysis. Future work will explore the impact of the BIGIS_DSS system in other areas of public health as using BIGIS_DSS to develop slums in development countries.

\section{REFERENCES}

[1] Anton F, Oldfield E, Coleman DJ,Towards web-based representation aand processing of health information Gao S, Mioc D, Yi X, Innternational Journal of Health Geographics 2009, 8:3

[2] Ben,Eazzetts ,GIS:The Next generation The Convergence of Technologies ,map Middle east,USA 2009

[3] Etienne Dubé,Thierry Badard ,An Introduction to geomonderian and spatialytics, Laval University, Quebec, Canada,2009

[4] Geoffrey M Jacquez and Robert Rommel, Local indicators of geocoding accuracy (LIGA): theory and application, International Journal of Health Geographics 2009, 8:60doi:10.1186/1476-072X-8-60

[5] Goldberg D: A Geocoding Best Practices Guide. Springfield, IL North American Association of Central Cancer Registries, 2008.

[6] Health indicators ,http://www.mohp.gov.eg/sec/About/engaza/2.doc

[7] Henry KA, Boscoe FP: Estimating the accuracy of geographical imputation .International Journal of Health Geographics 2008, 7:3.

[8] Kravets N, Hadden W: The accuracy of address coding and the effects of coding errors. Health Place 2007, 13:293-298.

[9] Matthew, Laurence Scotch, AN OLAP-GIS SYSTEM FOR NUMERICAL-SPATIAL PROBLEM SOLVING IN COMMUNITY HEALTH ASSESSMENT ANALYSIS, University of Pittsburgh ,2006

[10] Monaco Va1,parmanto Bambang, Scotch Matthew, Evaluation of SOVAT: An OLAP-GIS Decision Support System for Community Health Assessment Data Analysis, BMC Medical Informatics and Decision Making, Year :2008,issue 1 ,pp:10,Vol:8

[11] Philip ,Russom, Data Requirements for Advanced Analytics, TDWI Checklist report,2008

[12] Refaat M Kamell and Samir M Wassif, Population Problem In Egypt As One of The Priority Health Problems In Tropical Areas Surgery 
[13] Department, Faculty of Medicine, Ain-Shams University and Community Medicine Department, Faculty of Medicine, Zagazig University, Egypt_2008

[14] Rushton G, Armstrong M, Gittler J, Greene B, Pavlik C, West M, Zimmerman D. Boca Raton, Statistical methods for incompletely and incorrectly geocoded cancer data. In Geocoding Health Data. PL: CRC Press, 2008

[15] Space-Time Intelligence System to improve retail decision making, http://www.terraseer.com/products_stis.php

[16] Terban, Efraim., Decision Support and Business Intelligence Systems [et al.].8th ed.p.cm.2007

[17] Ward MH, Nuckols JR, Giglierano J, Bonner MR, Wolter C, Airola M, Mix W, Colt JS, Hartge P: Positional accuracy of two methods of geocoding. Epidemiology 2005, 16:542-547

[18] Wassif S.M and Amany R.: Spot lights on the demographic profile of Egypt, The Egyptian journal of Community Medicine 2008Vol. 26, No.1

[19] Wei Gu, Xin Wang, S Elizabeth McGregor, Optimization of preventive health care facility locations, Canada,2010

[20] Zahran M.: Evaluation of census,2006. Al Ahram newspaper, 4/4/2007.

[21] Zandbergen PA: Positional Accuracy of Spatial Data: Non-Normal Distributions and a Critique of the National Standard for Spatial Data Accuracy Transactions in GIS 2008, 12:103-130.

[22] Zimmerman D, Fang X, Mazumdar S, Rushton G: Modeling the probabilitydistribution of positional errors incurred by residential address geocoding International Journal of Health Geographics 2007, $6: 1$.
Booman M, et al.: Using a geographical information system to plan a malaria control programme in South Africa.Bull World Health Organ 2000, 78:1438-1444.

[23] Peters DH, Garg A, Bloom G, Walker DG, Brieger WR, Rahman MH: Poverty and access to health care in developing countries.

[24] Annals of the New York Academy of Sciences 2008, 161171.1136(Reducing the Impact of Poverty on Health and Human Development: Scientific Approaches)

[25] Müller I, Smith T, Mellor S, Rare L, Genton B: The effect of distance from home on attendance at a small rural health centre in Papua New Guinea.International Journal of Epidemiology 1998, 27(5):878.

[26] Arcury TA, Gesler WM, Preisser JS, Sherman J, Spencer J, Perin J: The effects of geography and spatial behavior on health care utilization among the residents of a rural region.Health Services Research 2005, 40(1):135-156.

[27] Tanser F, Gijsbertsen B, Herbst K: Modelling and understanding primary health care accessibility and utilization in rural South Africa: An exploration using a geographical information system.Social Science \& Medicine 2006, 63(3):691-705.

[28] Tanser F, Wilkinson D: Spatial implications of the tuberculosis DOTS strategy in rural South Africa: a novel application of geographical information system and global positioning system technologies.Tropical Medicine \& International Health 1999, 4(10):634-638.

[29] Perry B, Gesler W: Physical access to primary health care in Andean Bolivia.Social Science \& Medicine 2000, 50(9):1177-1188.

[30] McLafferty SL: GIS and health care, 2003. 